\title{
Eleven-year follow-up of a prospective study of Zirconia implant abutments supporting single all-ceramic crowns in anterior and premolar regions
}

\author{
Zembic, Anja ; Philipp, Alexander Otto Hermann ; Hämmerle, Christoph Hans Franz ; Wohlwend, Arnold ;
} Sailer, Irena

\begin{abstract}
BACKGROUND Clinical studies on zirconia abutments report very good survival rates and biological and technical results, but few have an observation period of more than 5 years. PURPOSE The aim of this study was to assess the long-term performance of customized zirconia implant abutments supporting all-ceramic crowns. MATERIALS AND METHODS Twenty-seven patients receiving 54 single implants were included (25 incisors, 14 canines, 15 premolars in both jaws). Yttria-stabilized zirconia abutments were screwed to the implants with a defined torque. All-ceramic crowns were adhesively cemented onto the abutments. The implants, abutments, and crowns were clinically and radiographically examined after 11 years of use. Modified United States Public Health Service (USPHS) criteria were used to assess technical outcomes: fracture of abutmen$\mathrm{t}$ /crown framework/veneering ceramic, loosening of abutment screw/crown, marginal adaptation, anatomical form, occlusal wear, and abutment fit. The biological parameters were pocket probing depth, plaque control record, bleeding on probing, papilla index, and gingival/mucosal recession at implants and neighboring natural teeth. The cumulative success rate of abutments and crowns was calculated by the Kaplan-Meier method. The results of the USPHS criteria were analyzed descriptively. RESULTS Sixteen patients with 31 zirconia abutments were examined at $11.3( \pm 0.9)$ years after implantation. No abutment or crown was lost. The cumulative success rate was $96.3 \%$ for abutments and $90.7 \%$ for crowns. Two abutment screws loosened, and three crowns exhibited minor chipping. There were no biological complications. CONCLUSIONS Customized zirconia single implant abutments exhibited excellent long-term outcomes in anterior and premolar regions.
\end{abstract}

DOI: https://doi.org/10.1111/cid.12263

Posted at the Zurich Open Repository and Archive, University of Zurich ZORA URL: https://doi.org/10.5167/uzh-98627

Journal Article

Accepted Version

Originally published at:

Zembic, Anja; Philipp, Alexander Otto Hermann; Hämmerle, Christoph Hans Franz; Wohlwend, Arnold; Sailer, Irena (2015). Eleven-year follow-up of a prospective study of Zirconia implant abutments supporting single allceramic crowns in anterior and premolar regions. Clinical Implant Dentistry and Related Research, 17 Suppl:e417e426.

DOI: https://doi.org/10.1111/cid.12263 


\title{
11-year follow-up of a prospective study of zirconia implant- abutments supporting single all-ceramic crowns in anterior and premolar regions.
}

\author{
Anja Zembic $^{\text {ab }}$, Alexander Otto Hermann Philipp ${ }^{\text {cd }}$, Christoph Hans Franz Hämmerle ${ }^{\mathrm{e}}$, \\ Arnold Wohlwend ${ }^{\mathrm{f}}$, Irena Sailer ${ }^{\mathrm{g}}$
}

\begin{abstract}
${ }^{a}$ Assistant Professor, Division of Fixed Prosthodontics, University of Berne, Switzerland
${ }^{b} \mathrm{PhD}$ Student, Department of Oral Implantology and Prosthetic Dentistry, Academic Center for Dentistry Amsterdam (ACTA), Move Research Institute, The Netherlands

${ }^{c}$ Private Practice, Effretikon, Switzerland

${ }^{\mathrm{d}}$ Research Fellow, Clinic for Preventive Dentistry, Periodontology and Cariology, Center for Dental Medicine, University of Zurich, Switzerland

${ }^{e}$ Professor and Head, Clinic of Fixed and Removable Prosthodontics and Dental Material Science, Center for Dental Medicine, University of Zurich, Switzerland

${ }^{\mathrm{f}}$ Master Dental Technician, Private Dental Technical Laboratory, Schellenberg, Liechtenstein ${ }^{g}$ Professor and Head, Clinic of Fixed Prosthodontics and Biomaterials, School of Dental Medicine, University of Geneva, Switzerland
\end{abstract}

Keywords: implant abutments, ceramics, zirconia, survival rate, dental implants, singletooth, outcome assessment

Running head: 11-year follow-up of zirconia implant abutments

\author{
Corresponding author: Dr. Anja Zembic \\ Department of Oral Implantology and Prosthetic Dentistry \\ Academic Centre for Dentistry Amsterdam (ACTA) \\ Gustav Mahlerlaan 3004 \\ 1081 LA Amsterdam, The Netherlands \\ Phone: +310205980412 \\ Fax: +310205980333 \\ e-mail: a.zembic@acta.nl
}




\section{ABSTRACT}

Background: Clinical studies on zirconia abutments report very good survival rates and biological and technical results with a maximum observation period of 5 years.

Purpose: The aim of this study was to assess the long-term performance of customized zirconia implant-abutments supporting all-ceramic crowns.

Materials and Methods: Twenty-seven patients receiving 54 single implants were included (25 incisors, 14 canines, 15 premolars in both jaws). Yttrium-stabilized zirconia abutments were screw-retained to the implants with a defined torque. All-ceramic crowns were adhesively cemented onto the abutments. The implant-abutments and crowns were clinically and radiographically examined at 11 years of function. Modified United States Public Health Service (USPHS) criteria were used to assess technical outcomes: fracture of abutment/crown framework/veneering ceramic, loosening of abutment screw/crown, marginal adaptation, anatomical form, occlusal wear and abutment fit. The biological parameters were pocket probing depth, plaque control record, bleeding on probing, papilla index and gingival/mucosal recession at implants and neighboring natural teeth.

The cumulative success rate of abutments and crowns was calculated with Kaplan-Meier statistics. The results of the USPHS criteria were analyzed descriptively.

Results: Sixteen patients with 31 zirconia abutments were examined at $11.3( \pm 0.9)$ years. No abutment or crown was lost. The cumulative success rate was $96.3 \%$ for abutments and 90.7\% for crowns. Two abutment screws loosened and 3 crowns exhibited minor chipping. There were no biological complications.

Conclusions: Customized single zirconia implant-abutments exhibited excellent long-term outcomes in anterior and premolar regions. 


\section{INTRODUCTION}

Implant-supported single-crowns are a valid and established alternative to conventional fixed dental prostheses (FPDs) for single-tooth replacement. ${ }^{17}$

One major reason is that implant reconstructions exhibit very good survival rates today. The probability of survival for conventional tooth-borne FPDs was calculated $89.1 \%$ at 10 years, whereas it was even slightly superior with $89.4 \%$ for single implant reconstructions at 10 years according to the results of two systematic reviews. ${ }^{22,49}$

Besides sound survival rates, the goal of an implant treatment is to achieve a harmonious reconstruction that cannot be distinguished from natural teeth by the naked eye. This is of particular importance in the challenging and most exposed anterior region of the jaws.

The appearance of a tooth within the dento-gingival complex is composed by the optical characteristics of the crown and the complexion of its surrounding soft tissue, previously referred to as the 'white' and 'pink' esthetics. ${ }^{31,34,38}$ For satisfying 'white' and 'pink' esthetics of an implant reconstruction, the color and shape of the implant crown and of the peri-implant soft tissue are crucial. ${ }^{13,29,44,58}$

Interestingly, a high number of human studies investigated the influence of the abutment material on the mucosal color over the past years. ${ }^{7,16,20,36,41,54,61}$

The existent abutment materials vary from gold or titanium to the high-strength ceramics alumina and zirconia. ${ }^{57}$ While titanium abutments may cause a greyish discoloration of the peri-implant mucosa, ceramic abutments are reported to minimize soft tissue shadowing due to their color and the enhanced translucency and may lead to optimal esthetic results in combination with all-ceramic crowns. ${ }^{35}$ Moreover, a correlation was found between mucosa thickness and mucosa color, dependent on the abutment material used. ${ }^{20,21}$ As a result, ceramic abutments are applied more and more often in esthetically demanding areas.

The high-strength ceramic zirconia was introduced in 1995 as abutment material and its use is steadily increasing. ${ }^{48}$ Superior material stability compared to conventional ceramics combined with a more advantageous color is the main advantage of zirconia over titanium.

The type of zirconia used in dentistry is partially stabilized tetragonal zirconia poly-crystals. This specific type of zirconia exhibits very high fracture toughness, i.e. resistance towards crack propagation, through a phenomenon called "transformation toughening". 37 
This phenomenon could be one reason for the so far excellent clinical survival rates. Even though, the transformation from tetragonal to monoclinic zirconia lowers the material's fracture toughness over time. ${ }^{47}$

Clinical studies on zirconia abutments report very good survival rates and biological and technical results with a maximum observation period of 5 years. $8,11,13,26,33,43,59,61$ Two systematic reviews compared ceramic abutments to metal abutments. ${ }^{41,60}$ There were no differences with regard to the survival rates, or the technical and biological outcomes after 5 years of clinical function. ${ }^{41,57}$

Albeit 5 years is a rather short time for zirconia abutments to be in function. In vitro studies demonstrated a decrease of $50 \%$ of the fracture toughness, when zirconia was exposed to a simulated 10-year aging process in a humid environment. ${ }^{47}$ Up to now, there is no clinical long-term data of zirconia abutments available, since existing studies report on the longest follow-up of 5 years. ${ }^{8,11,13,26,33,43,59,61}$ There is one study with 4 patients receiving 6 single implants (3 maxillary central incisors, 3 canines) and all-ceramic crowns which were adhesively cemented to zirconia abutments. ${ }^{12}$ No abutment fractures occurred at a follow-up of 6 years (mean observation time 74.6 months). Thus, it remains to be clarified whether or not aging leads to a clinically relevant reduction of the physical properties of zirconia in the long run.

The aim of the following study, therefore, was to test the clinical long-term outcomes of single implant zirconia abutments supporting all-ceramic crowns in anterior and premolar regions. The present manuscript is an update of the previously published manuscript on the 4year results. ${ }^{13}$ 


\section{MATERIAL \& METHODS}

Study design and patient selection

Twenty-seven patients (16 women, 11 men) with 54 missing single teeth in need to be replaced by implants in anterior and premolar regions of both jaws were included in this prospective clinical study. The inclusion criteria were listed in the previous manuscript. ${ }^{13}$

All patients were thoroughly informed about the purpose and protocol of the planned investigation and informed consent was obtained.

\section{Surgical procedures}

Implants (Brånemark system Mk II Regular Platform implants, Nobel Biocare, Gothenburg, Sweden) with an external hexagon were placed according to a standard, 2-stage protocol. ${ }^{1}$ Approved criteria were used to define implant success. ${ }^{2}$ Abutment connection was performed after the healing periods of up to 6 months.

\section{Prosthetic procedures}

An impression on implant level was performed with a polyether material (Permadyne, 3M Espe, Seefeld, Germany) using a prefabricated impression coping. Screw-retained acrylic implant provisionals were manufactured and inserted onto the implants. The peri-implant soft tissue was conditioned in several appointments by continuous adding of composite to the provisional crown until a most harmonious shape of the emergence profile was achieved. Subsequently, an impression with polyether material (Permadyne, 3M Espe, Seefeld, Germany) was taken at fixture level using an individualized impression coping according to a described method. ${ }^{14}$

One experienced dental technician made the customized abutment ingots (Metoxit, Thayngen, Switzerland). For this, firstly the wax-up of the prospective definitive crown was tried-in at the patient and esthetic adjustments were performed, if needed. Then, the desired custom shape of the abutment was created out of resin (GC Pattern Resin LS, Leuven, Belgium) (pro-abutment) according to the shape of the crown wax-up to ideally support the reconstruction. Thereafter, the dental technician chose the most suitable diameter of the prefabricated yttrium-stabilized zirconia abutment ingots. The ingot was customized manually with diamond burs guided by copy milling so as to reproduce the pro-abutment. Attention was paid to ensure a minimal abutment wall thickness of $0.5 \mathrm{~mm}$. The abutment was clinically tried-in and corrections with concern to emergence profile and likewise 
location of the prospective crown margin were made either intra- or extraorally with diamond burs. Together with the implant abutment, an all-ceramic crown was produced on the basis of the shape of the wax-up (Empress I, Ivoclar Vivadent, Schaan, Lichtenstein). The completed zirconia abutment was screw-retained to the implant with a gold screw (DCA 1045, Brånemark system) and a defined torque of $32 \mathrm{Ncm}$, according to the manufacturer's recommendations. The screw access hole was covered with guttapercha and composite and the all-ceramic crown was adhesively cemented onto the zirconia abutment (Panavia TC, Kuraray, Okayama, Japan). Baseline was set at abutment/crown insertion.

Abutments/crowns that remained inserted during the observation period were considered as "survival".

Abutments/crowns that did not have any event were considered as "success".

\section{Clinical parameters}

Clinical examinations were performed at 1 month, and at 1, 4 and 11 years of follow-up. Implants, abutments and crowns were evaluated for their survival, and technical and biological outcomes.

Modified United States Public Health Service (USPHS) criteria were used for the assessment of the technical outcome of the crowns at 11 years..$^{5}$ A crown was rated Alfa (A) if no problem occurred, Bravo (B) if small but clinically acceptable defects were found, Charlie (C) if a crown was clinically unacceptable, due to any issue, but still justifiable to remain in clinical function (repairable problem up to a clinical acceptable level through e.g. polishing), and Delta (D) if the crown was not justifiable to remain in clinical function due to a non-repairable problem, i.e. the crown had to be replaced.

The evaluated parameters included fracture of the abutment and/or crown framework, fracture of the veneering ceramic, loosening of the abutment screw, loosening of the crown (decementation), marginal adaptation, anatomical form and occlusal wear. Additionally, the fit of the abutment was assessed by rating the connection between abutment and implant radiographically. Thereby, the connection was defined 0 if no gap was clinically detectable, 1 in case of a gap between abutment and crown and 2, if there was a gap between abutment and implant.

The biological outcome was assessed with a periodontal probe (PCB 12; Hu-Friedy, Leimen, Germany) at implants (test) and neighboring natural teeth (control) at four sites per 
implant/tooth. Mean values were calculated. Pocket probing depths (PPD), and presence or absence of plaque (modified Plaque Index, mPII) and bleeding on probing (BOP) were recorded. ${ }^{30}$ The distance from the crown margin to the margo mucosae of the implant site was measured as compared to the distance of the cement-enamel-junction to the margo gingivae of the neighboring natural teeth (Figure 2,3). Besides, the mesial and distal papillae of the implant site and adjacent natural teeth were judged by means of the index published by Jemt. ${ }^{18}$ Orthoradial radiographs (Kodak Ultra Speed, Eastman Kodak Co., Rochester, New York, USA) were taken of the implants with the long-cone parallel technique at 11 years of follow-up (Figures 1-4). ${ }^{53}$ Previously, bone levels have been assessed at baseline, 1 and 4 years of follow-up. ${ }^{13}$

Mesial and distal bone levels were measured and the peri-implant bone loss was calculated from baseline to the 11-year follow-up. For this purpose, the radiographs were digitized and the distance in $0.1 \mathrm{~mm}$ increments was calculated from the implant-abutment connection as reference line to the most coronal bone-to-implant-contact. The known distance between implant threads $(0.6 \mathrm{~mm})$ was used for calibration.

\section{Statistical analysis}

The cumulative success rate of abutments and reconstructions was calculated with KaplanMeier statistics. Mean values and standard deviations were used for the statistical analysis of biological and technical factors. The analysis was performed using a statistical software program (SPSS, Version 17). The level of significance was at $0.05 \%$. The results of the USPHS criteria were analyzed descriptively. 


\section{RESULTS}

Sixteen patients ( 9 women, 7 men) with 31 zirconia abutments (15 maxillary incisors, 9 canines, 4 premolars and 3 mandibular premolars) were examined after a mean observation time of 11.3 (SD 0.9) years. Eleven patients (7 women, 4 men) with 23 implants/ abutments did not show up for the 11-year follow-up and could not be tracked.

None of the examined abutments and crowns was lost. Hence, the 11-year survival rate was $100 \%$ for both abutments and crowns.

Apart from the previously reported 2 abutment screw loosenings and 3 chippings of veneering ceramics, no further technical failures occurred up to the 11 year follow-up visit, neither at abutments nor at crowns (Figure 2). ${ }^{13}$

Therefore the Kaplan-Meier cumulative success rate was $96.3 \%$ for the evaluated abutments and $90.7 \%$ for the crowns, respectively. With regard to the USPHS criteria, the marginal adaptation was clinically acceptable for all crowns (Figure 1-4, Table 1).

The fit of all examined abutments/ crowns was satisfactory (Table 2).

The biological integration of the implants, abutments and crowns was excellent with no biological complications at the implant sites. There were no significant differences for none of the evaluated parameters between test and control sites (Table 3).

The mean peri-implant bone loss from baseline to 11 years amounted to $1.6 \mathrm{~mm}$ (SD $0.7 \mathrm{~mm}$ ) (Figures 1-4). 


\section{DISCUSSION}

In this long-term prospective clinical study of zirconia abutments supporting all-ceramic single implant crowns in anterior and premolar regions, no abutment and/or crown fractures occurred and no loss of implants/abutments/crowns were found, resulting in a high survival rate. Furthermore, the technical outcomes were very good as well. Only in a few sites technical complications like loosening of abutment screws or chipping of the veneering ceramic occurred. Finally, the biological integration of the zirconia- based implant reconstructions was excellent with low amounts of bone loss and no signs of mucosal inflammation.

One distinctive feature of zirconia is its crack resistance, also called „transformation toughening“ ${ }^{37}$ This phenomenon increases the fracture toughness of the material and might be the explanation for the so far excellent clinical survival rates in the present study. After more than 10 years of function the zirconia abutments and supported crowns reached $100 \%$ of survival and a complication-free rate of $96.3 \%$ in the present study. This result is very promising since the estimated 5-year cumulative survival rate of $99 \%$ and $97.5 \%$ reported for ceramic abutments in two systematic reviews are only slightly higher. ${ }^{41,57}$ The present outcome may lead to the assumption, that ageing of zirconia abutments seems not to be a clinically relevant issue for up to and more than 10 years in function. More long-term data is, however, needed to further analyze this issue.

Today, zirconia abutments are being increasingly used in esthetic regions. However, in general not much information on zirconia abutments is available in the literature. In the above mentioned reviews, a relatively low number of zirconia abutments (124 zirconia abutments) could be included because of the fact that only a limited number of clinical studies on zirconia abutments were published so far. ${ }^{13,15,33,41,59}$ In addition, no clinical long-term data on zirconia abutments exist so far with the present study reporting on the longest follow-up period. Still, the available clinical studies support the use of zirconia abutments due to their successful outcomes at up to 5 years in function. ${ }^{15,26,59}$

The present study reports on the long-term performance of externally connected zirconia abutments. Available clinical studies on internally connected zirconia abutments likewise support the successful use with no abutment fractures up to 5 years of service. ${ }^{8,15,26,33} \mathrm{~A}$ series of in vitro studies compared the stability of internally and externally connected zirconia 
abutments. $^{25,42,52}$ The results suggest that higher loads are needed until fracture of internally connected zirconia abutments compared to externally connected abutments. ${ }^{25,}$ 42, 52 Taking into account the excellent present long-term results for externally connected abutments, one might expect similar or even more favorable clinical outcomes for internally connected abutments on long-term.

Despite these positive findings, technical complications leading to the loss of the zirconia abutments, most specifically fractures, have also been reported in one retrospective study and two case reports. ${ }^{11,40,55}$ No detailed information was given on the fabrication method of the fractured abutments. ${ }^{11,40,55}$ It is well known that factors like the processing technique or thickness of the abutment walls may affect the stability of zirconia implant abutments. ${ }^{23,24,27}$ Most studies on zirconia abutments, however, do not depict neither fabrication method nor abutment thickness. ${ }^{23,24,27,32,56}$

When being milled out of a zirconia block, the abutment wall thickness should not go below $0.5 \mathrm{~mm}$, which was assured in the present study. ${ }^{10}$ A wall thickness of at least $0.7 \mathrm{~mm}$ for zirconia abutments was advised in another study. ${ }^{6}$ Thus, special care should be given to the manufacturing and handling of zirconia abutments and more information on both should be provided in future clinical studies in order to draw conclusions for the clinical success of zirconia abutments.

It has been shown that different types of surface treatments of zirconia, like e.g. grinding induce different amounts of surface roughness. Surface roughness may negatively influence the mechanical stability of the material and increase the risk for fracture of the abutments over time. ${ }^{28}$ For this reason, the abutments were polished to high glaze prior to clinical application in the present study.

The frequency of $6.5 \%$ abutment screw loosening is similar in the present study to a prospective clinical study on single implants with external connection. ${ }^{3}$ In that study, $7.3 \%$ abutment screws loosened during the 3-year observation period. ${ }^{3}$ These rates are higher than the estimated rate of $1 \%$ at 5 years as reported in a systematic review on abutments both with internal and external connection. ${ }^{41}$ The authors found a trend toward fewer abutment screwloosening rates for internally connected abutments compared to externally connected abutments. ${ }^{41}$ In agreement with this trend no event of screw loosening was found in one study on internally connected zirconia abutments after 3 years. ${ }^{15}$ A more recent study found $2.7 \%$ 
abutment screw loosening for internally connected zirconia abutments after 5 years of function. ${ }^{26}$ Loosening of abutment screws with the external-hex implant systems was a wellknown technical problem in the past. ${ }^{15}$ Nowadays, the stability of the external implantabutment connection improved by altering the screw alloys and their surfaces and applying proper torque values to establish higher initial preloads. ${ }^{15,19}$ This might explain, why another systematic review did not find any influence of the implant-abutment connection on the incidence of abutment screw loosening (provided that proper antirotational features and torque were applied). ${ }^{50}$ In addition, there was a high accuracy of fit of the abutment in the present study due to the prototype abutment. The occurrence of chipping in the present study $(9.7 \%)$ is in accordance with a study on all-ceramic crowns supported by zirconia with a chipping rate of $10 \%$, even after 12 months. ${ }^{33}$ The crowns were cemented with glass ionomer cement in contrast to the adhesively cemented crowns in the present study. ${ }^{33}$ A more recent study found even $10.8 \%$ chipping after 5 years for temporarily cemented all-ceramic crowns supported by zirconia abutments. ${ }^{26}$ Whether the cement had an influence on the chipping rate remains to be further analyzed.

A systematic review and a study on all-ceramic crowns supported by zirconia abutments studies found less chipping with an estimated rate of $4 \%$ at 3 and 5 years. ${ }^{15,41}$ A recent systematic review found solely $3.2 \%$ chipping at crowns supported by zirconia abutments. ${ }^{60}$ Thus, other factors like e.g. an insufficient cooling time of zirconia which importance was underrated in the beginnings of the use of zirconia might have contributed to the high chipping rates. ${ }^{51}$

The present excellent biological integration of zirconia abutments is in accordance with several clinical studies substantiating less inflammation and bacterial adhesion compared to titanium. ${ }^{9,} 39,45$

The bone loss in the present study is within the regular range for this type of implant, mostly occurring within the first year after loading. ${ }^{4,}{ }^{46}$ In addition, the bone loss correlates to the formerly set implant success criteria, wherein bone loss should not exceed $2 \mathrm{~mm}{ }^{2}$ 


\section{CONCLUSIONS}

The following conclusions can be drawn within the limitations of the present study:

- Customized zirconia implant-abutments exhibited excellent long-term survival and technical and biological outcomes and can be used to support single-implant crowns in anterior and premolar regions

- Zirconia abutments seem not to be increasingly prone to fractures over time

- The influence of aging on the physical properties of zirconia abutments being in clinical use remains unclear

- More clinical long-term studies on zirconia implant abutments including report on manufacturing and handling are needed to support the findings of this study

\section{ACKNOWLEDGEMENT}

The authors would like to thank Dr. Malgorzata Roos, Department of Biostatistics, University of Zurich, Switzerland for the help with the statistical analysis of the present data and Mrs. Nadja Glauser, Clinic of Fixed and Removable Prosthodontics and Dental Material Science, University of Zurich, Switzerland for her help with organizing and scanning of the radiographs. 


\section{REFERENCES}

1. Adell R. Tissue integrated prostheses in clinical dentistry. Int Dent $J$ 1985; 35: 259265.

2. Albrektsson T, Zarb G, Worthington P, Eriksson AR. The long-term efficacy of currently used dental implants: a review and proposed criteria of success. Int J Oral Maxillofac Implants 1986; 1: 11-25.

3. Andersen E, Saxegaard E, Knutsen BM, Haanaes HR. A prospective clinical study evaluating the safety and effectiveness of narrow-diameter threaded implants in the anterior region of the maxilla. Int J Oral Maxillofac Implants 2001; 16: 217-224.

4. Astrand P, Engquist B, Dahlgren S, Grondahl K, Engquist E, Feldmann H. Astra Tech and Branemark system implants: a 5-year prospective study of marginal bone reactions. Clin Oral Implants Res 2004; 15: 413-420.

5. Bayne SC, Schmalz G. Reprinting the classic article on USPHS evaluation methods for measuring the clinical research performance of restorative materials. Clin Oral Investig 2005; 9: 209-214.

6. Blatz MB, Bergler M, Holst S, Block MS. Zirconia abutments for single-tooth implants--rationale and clinical guidelines. J Oral Maxillofac Surg 2009; 67: 74-81.

7. Bressan E, Paniz G, Lops D, Corazza B, Romeo E, Favero G. Influence of abutment material on the gingival color of implant-supported all-ceramic restorations: a prospective multicenter study. Clin Oral Implants Res 2011; 22: 631-637.

8. Canullo L. Clinical outcome study of customized zirconia abutments for singleimplant restorations. Int J Prosthodont 2007; 20: 489-493.

9. Degidi M, Artese L, Scarano A, Perrotti V, Gehrke P, Piattelli A. Inflammatory infiltrate, microvessel density, nitric oxide synthase expression, vascular endothelial growth factor expression, and proliferative activity in peri-implant soft tissues around titanium and zirconium oxide healing caps. J Periodontol 2006; 77: 73-80.

10. Denry I, Kelly JR. State of the art of zirconia for dental applications. Dent Mater 2008; 24: 299-307.

11. Ekfeldt A, Furst B, Carlsson GE. Zirconia abutments for single-tooth implant restorations: a retrospective and clinical follow-up study. Clin Oral Implants Res 2011; 22: 1308-1314.

12. Glauer R, Wohlwend, A., Studer, S. Application of Zirconia Abutments on Singletooth Implants in the Maxillary Esthetic Zone. A 6-year clinical and radiographic follow-up report. Applied Osseointegration Research 2004; 4: 41-45.

13. Glauser R, Sailer I, Wohlwend A, Studer S, Schibli M, Scharer P. Experimental zirconia abutments for implant-supported single-tooth restorations in esthetically demanding regions: 4-year results of a prospective clinical study. Int J Prosthodont 2004; 17: 285-290.

14. Hinds KF. Custom impression coping for an exact registration of the healed tissue in the esthetic implant restoration. Int J Periodontics Restorative Dent 1997; 17: 584-591.

15. Hosseini M, Worsaae N, Schiodt M, Gotfredsen K. A 3-year prospective study of implant-supported, single-tooth restorations of all-ceramic and metal-ceramic materials in patients with tooth agenesis. Clin Oral Implants Res 2012.

16. Ishikawa-Nagai S, Da Silva JD, Weber HP, Park SE. Optical phenomenon of periimplant soft tissue. Part II. Preferred implant neck color to improve soft tissue esthetics. Clin Oral Implants Res 2007; 18: 575-580.

17. Jemt T. Modified single and short-span restorations supported by osseointegrated fixtures in the partially edentulous jaw. J Prosthet Dent 1986; 55: 243-247. 
18. Jemt $\mathrm{T}$. Regeneration of gingival papillae after single-implant treatment. Int $J$ Periodontics Restorative Dent 1997; 17: 326-333.

19. Jorneus L, Jemt T, Carlsson L. Loads and designs of screw joints for single crowns supported by osseointegrated implants. Int J Oral Maxillofac Implants 1992; 7: 353-359.

20. Jung RE, Holderegger C, Sailer I, Khraisat A, Suter A, Hammerle CH. The effect of all-ceramic and porcelain-fused-to-metal restorations on marginal peri-implant soft tissue color: a randomized controlled clinical trial. Int J Periodontics Restorative Dent 2008; 28 : 357-365.

21. Jung RE, Sailer I, Hammerle CH, Attin T, Schmidlin P. In vitro color changes of soft tissues caused by restorative materials. Int J Periodontics Restorative Dent 2007; 27: 251257.

22. Jung RE, Zembic A, Pjetursson BE, Zwahlen M, Thoma DS. Systematic review of the survival rate and the incidence of biological, technical, and aesthetic complications of single crowns on implants reported in longitudinal studies with a mean follow-up of 5 years. Clin Oral Implants Res 2012; 23 Suppl 6: 2-21.

23. Kosmac T, Oblak C, Jevnikar P, Funduk N, Marion L. The effect of surface grinding and sandblasting on flexural strength and reliability of Y-TZP zirconia ceramic. Dent Mater 1999; 15: 426-433.

24. Kosmac T, Oblak C, Jevnikar P, Funduk N, Marion L. Strength and reliability of surface treated Y-TZP dental ceramics. J Biomed Mater Res 2000; 53: 304-313.

25. Leutert CR, Stawarczyk B, Truninger TC, Hammerle CH, Sailer I. Bending moments and types of failure of zirconia and titanium abutments with internal implant-abutment connections: a laboratory study. Int J Oral Maxillofac Implants 2012; 27: 505-512.

26. Lops D, Bressan E, Chiapasco M, Rossi A, Romeo E. Zirconia and titanium implant abutments for single-tooth implant prostheses after 5 years of function in posterior regions. Int J Oral Maxillofac Implants 2013; 28: 281-287.

27. Luthardt RG, Holzhuter M, Sandkuhl O, Herold V, Schnapp JD, Kuhlisch E, Walter M. Reliability and properties of ground Y-TZP-zirconia ceramics. J Dent Res 2002; 81: 487491.

28. Luthardt RG, Holzhuter MS, Rudolph H, Herold V, Walter MH. CAD/CAMmachining effects on Y-TZP zirconia. Dent Mater 2004; 20: 655-662.

29. Marinello CP, Meyenberg KH, Zitzmann N, Luthy H, Soom U, Imoberdorf M. Single-tooth replacement: some clinical aspects. J Esthet Dent 1997; 9: 169-178.

30. Mombelli A, van Oosten MA, Schurch E, Jr., Land NP. The microbiota associated with successful or failing osseointegrated titanium implants. Oral Microbiol Immunol 1987; 2: $145-151$.

31. Morley J, Eubank J. Macroesthetic elements of smile design. J Am Dent Assoc 2001; 132: $39-45$.

32. Nguyen HQ, Tan KB, Nicholls JI. Load fatigue performance of implant-ceramic abutment combinations. Int J Oral Maxillofac Implants 2009; 24: 636-646.

33. Nothdurft F, Pospiech P. Prefabricated zirconium dioxide implant abutments for single-tooth replacement in the posterior region: evaluation of peri-implant tissues and superstructures after 12 months of function. Clin Oral Implants Res 2010; 21: 857-865.

34. Oringer RJ, Iacono VJ. Periodontal cosmetic surgery. J Int Acad Periodontol 1999; 1: 83-90.

35. Ormianer Z, Schiroli G. Maxillary single-tooth replacement utilizing a novel ceramic restorative system: results to 30 months. J Oral Implantol 2006; 32: 190-199. 
36. Park SE, Da Silva JD, Weber HP, Ishikawa-Nagai S. Optical phenomenon of periimplant soft tissue. Part I. Spectrophotometric assessment of natural tooth gingiva and periimplant mucosa. Clin Oral Implants Res 2007; 18: 569-574.

37. Piconi C, Maccauro G. Zirconia as a ceramic biomaterial. Biomaterials 1999; 20: 125.

38. Pini Prato G. Mucogingival deformities. Ann Periodontol 1999; 4: 98-101.

39. Rimondini L, Cerroni L, Carrassi A, Torricelli P. Bacterial colonization of zirconia ceramic surfaces: an in vitro and in vivo study. Int J Oral Maxillofac Implants 2002; 17: 793798.

40. Roe P, Kan JY, Rungcharassaeng K, Won JB. Retrieval of a fractured zirconia implant abutment using a modified crown and bridge remover: a clinical report. $J$ Prosthodont 2011; 20: 315-318.

41. Sailer I, Philipp A, Zembic A, Pjetursson BE, Hammerle CH, Zwahlen M. A systematic review of the performance of ceramic and metal implant abutments supporting fixed implant reconstructions. Clin Oral Implants Res 2009; 20 Suppl 4: 4-31.

42. Sailer I, Sailer T, Stawarczyk B, Jung RE, Hammerle CH. In vitro study of the influence of the type of connection on the fracture load of zirconia abutments with internal and external implant-abutment connections. Int J Oral Maxillofac Implants 2009; 24: 850858.

43. Sailer I, Zembic A, Jung RE, Siegenthaler D, Holderegger C, Hammerle CH. Randomized controlled clinical trial of customized zirconia and titanium implant abutments for canine and posterior single-tooth implant reconstructions: preliminary results at 1 year of function. Clin Oral Implants Res 2009; 20: 219-225.

44. Sanavi F, Weisgold AS, Rose LF. Biologic width and its relation to periodontal biotypes. J Esthet Dent 1998; 10: 157-163.

45. Scarano A, Piattelli M, Caputi S, Favero GA, Piattelli A. Bacterial adhesion on commercially pure titanium and zirconium oxide disks: an in vivo human study. $J$ Periodontol 2004; 75: 292-296.

46. Scheller H, Urgell JP, Kultje C, Klineberg I, Goldberg PV, Stevenson-Moore P, Alonso JM, Schaller M, Corria RM, Engquist B, Toreskog S, Kastenbaum F, Smith CR. A 5year multicenter study on implant-supported single crown restorations. Int J Oral Maxillofac Implants 1998; 13: 212-218.

47. Studart AR, Filser F, Kocher P, Gauckler LJ. Fatigue of zirconia under cyclic loading in water and its implications for the design of dental bridges. Dent Mater 2007; 23: 106-114.

48. Studer S, Zellweger U, Scharer P. The aesthetic guidelines of the mucogingival complex for fixed prosthodontics. Pract Periodontics Aesthet Dent 1996; 8: 333-341; quiz 342.

49. Tan K, Pjetursson BE, Lang NP, Chan ES. A systematic review of the survival and complication rates of fixed partial dentures (FPDs) after an observation period of at least 5 years. Clin Oral Implants Res 2004; 15: 654-666.

50. Theoharidou A, Petridis HP, Tzannas K, Garefis P. Abutment screw loosening in single-implant restorations: a systematic review. Int J Oral Maxillofac Implants 2008; 23: 681-690.

51. Tholey MJ, Swain MV, Thiel N. Thermal gradients and residual stresses in veneered Y-TZP frameworks. Dent Mater 2011; 27: 1102-1110.

52. Truninger TC, Stawarczyk B, Leutert CR, Sailer TR, Hammerle CH, Sailer I. Bending moments of zirconia and titanium abutments with internal and external implant-abutment connections after aging and chewing simulation. Clin Oral Implants Res 2012; 23: 12-18. 
53. Updegrave WJ. The paralleling extension-cone technique in intraoral dental radiography. Oral Surg Oral Med Oral Pathol 1951; 4: 1250-1261.

54. van Brakel R, Noordmans HJ, Frenken J, de Roode R, de Wit GC, Cune MS. The effect of zirconia and titanium implant abutments on light reflection of the supporting soft tissues. Clin Oral Implants Res 2011; 22: 1172-1178.

55. Villa R, Crespi R, Cappare P, Gherlone E. Immediate loading of a dental implant placed in fresh socket with acute dehiscence-type defect: a clinical case report. $J$ Periodontol 2010; 81: 953-957.

56. Wang H, Aboushelib MN, Feilzer AJ. Strength influencing variables on CAD/CAM zirconia frameworks. Dent Mater 2008; 24: 633-638.

57. Yildirim M, Edelhoff D, Hanisch O, Spiekermann H. Ceramic abutments--a new era in achieving optimal esthetics in implant dentistry. Int J Periodontics Restorative Dent 2000; 20: $81-91$.

58. Zarb GA, Lewis DW. Dental implants and decision making. J Dent Educ 1992; 56: 863-872.

59. Zembic A, Bosch A, Jung RE, Hammerle CH, Sailer I. Five-year results of a randomized controlled clinical trial comparing zirconia and titanium abutments supporting single-implant crowns in canine and posterior regions. Clin Oral Implants Res 2013; 24: 384390.

60. Zembic A, Kim, S., Zwahlen, M., Kelly, J.R. Systematic review of the survival rate and incidence of biological, technical and esthetic complications of single implant abutments supporting fixed prostheses. Int J Oral Maxillofac Implants 2013: accepted.

61. Zembic A, Sailer I, Jung RE, Hammerle CH. Randomized-controlled clinical trial of customized zirconia and titanium implant abutments for single-tooth implants in canine and posterior regions: 3-year results. Clin Oral Implants Res 2009; 20: 802-808. 